\title{
Qualidade da água em diferentes estádios de desenvolvimento do arroz irrigado
}

\author{
Joseline Molozzi(1) $^{(1)}$ Adilson Pinheiro(1) e Marcos Rivail da Silva(1)
}

(1)Universidade Regional de Blumenau, Caixa Postal 1.507, CEP 89010-971 Blumenau, SC. E-mail: jmolozzi@yahoo.com.br, pinheiro@furb.br, rivail@furb.br

\begin{abstract}
Resumo - Este trabalho teve como objetivo avaliar a qualidade da água utilizada para a rizicultura, em diferentes estádios de desenvolvimento da planta, no sistema de plantio pré-germinado. Foram analisadas as águas de irrigação e de drenagem no processo de cultivo. Foram escolhidas três áreas de amostragens, localizadas no Município de Gaspar, SC, que apresentam técnicas de cultivo semelhantes. A água utilizada para irrigação é retirada de um curso de água e devolvida após o uso no quarteirão, para o mesmo curso. Neste sistema não existem aportes de poluentes externos intermediários. Para avaliar a qualidade da água, foi utilizado o Índice de Qualidade de Água de Bascarán (IQAb). De acordo com os resultados, a água utilizada para irrigação apresenta qualidade imprópria (IQAb 40-50). A água de drenagem foi classificada, de modo geral, como desagradável (IQAb 30-40). Os parâmetros que mais influenciaram a diminuição do IQAb na água de drenagem foram a turbidez, fosfatos e DQO. Constatou-se que a fase de preparo do solo é a que provoca maior degradação da qualidade da água, na cultura orizícola.
\end{abstract}

Termos para indexação: rizicultura, irrigação, qualidade da água, índice de Bascarán.

\section{Quality of water in different periods of growth of flooded rice}

\begin{abstract}
The objective of this study was to evaluate the quality of the water used for rice irrigation, considering different periods of the plants growth, using the pre-germinated seeds planting technique. Irrigation and drainage water were analyzed during the process of tillage. Three sites of sampling located around the City of Gaspar SC, Brazil were chosen. All three sites presented similar techniques of tillage. The water used for the irrigation was collected from a watercourse and returned after it passed through the tillage. In this system there are no external or intermediary pollutant conductors. To evaluate the quality of water it was used the Quality of Water Index from Bascarán (IQAb). The results demonstrate that the water used for irrigation, enters in the tillage area with an improper quality (IQAb 40-50). Drainage water was classified as disagreable (IQAb 30-40). The parameters that influenced the decrease of IQAb in drainage water were the turbidity, phosphates and QOD. The decrease of drainage water quality was influenced by the vegetative period. This study determined that the major degradation of the quality of the water is due to the preparation of the soil.
\end{abstract}

Index terms: rice growing, irrigation, quality of water, index of Bascarán.

\section{Introdução}

No Brasil, o arroz é produzido sob diferentes sistemas de cultivo. No ano de 2001/2002, 32\% do arroz colhido no Brasil foi produzido em terras altas (sequeiro) e 68\% em várzeas (irrigado). Na Região Sul, na safra 2001/2002, cerca de 90,4\% da área cultivada foi em solos de várzea e 4,5\% no sistema de terras altas (Azambuja et al., 2004).

O sistema de plantio pré-germinado inicia-se em uma área previamente sistematizada e preparada, o que pode ser feito em presença de água ou em condições de solo seco, dependendo dos procedimentos adotados (Santos et al., 2002). Posteriormente, completa-se a lâmina de água, até se atingir o máximo de $5 \mathrm{~cm}$, para a semeadura. De 1 a 3 dias após a semeadura, retira-se a água. Nesse período, é comum colocar e retirar a água várias vezes, para auxiliar o processo de desenvolvimento do sistema radicular e, conseqüentemente, melhorar a fixação da planta ao solo.

Em Santa Catarina, observou-se que o uso da irrigação, no sistema pré-germinado, proporcionou aumento 
médio de 64\% na produtividade de grãos, em relação aos sistemas de semeadura em solo seco (Petrini et al., 2004). Contudo, para alcançar elevada produtividade no cultivo de arroz, depende-se da disponibilidade de água de boa qualidade (Costa et al., 2000). Conceitualmente, a qualidade da água refere-se àquelas características que influenciam sua adequabilidade ao uso específico. Na avaliação da água de irrigação, deveriam ser consideradas suas características físicas, químicas e biológicas, que, em sua maior parte, não são avaliadas pelos orizicultores.

Considerando-se que as práticas culturais envolvem revolvimento do solo e aplicação de agroquímicos, a cultura do arroz apresenta-se como potencial degradador da qualidade da água (Bethune et al., 2001). A implementação do sistema pré-germinado em lavouras de arroz irrigado, no Rio Grande do Sul e Santa Catarina, tem aumentado a demanda pela aplicação de herbicidas, inseticidas e fungicidas. Trabalhos realizados por Deschamps et al. (2003), em seis bacias no Estado de Santa Catarina, demonstram que alguns parâmetros, como o fosfato e a turbidez, ultrapassaram os limites máximos estabelecidos pela resolução do Conana 357/2005.

O monitoramento de parâmetros de qualidade da água constitui-se em ferramenta básica, para avaliar alterações ambientais causadas pela ação antrópica. Os índices de qualidade da água têm sido propostos com o objetivo de sintetizar as variáveis analisadas em um só número, que represente a condição e evolução da qualidade da água no tempo e no espaço. Esses índices podem ser usados como acessórios na interpretação de dados, auxiliando na avaliação dos resultados, e representam a qualidade da água numa escala numérica, pois fornecem um meio de julgar a efetividade do programa de controle ambiental. Além disso, permitem comparar condições da água, ao longo do tempo e em várias localizações geográficas, e possibilitam uma comunicação explícita entre profissionais e o público, já que a informação sobre a qualidade da água e a localização da poluição é transmitida em termos simples (Molozzi et al., 2005).

O objetivo deste trabalho foi avaliar a qualidade da água de irrigação e drenagem, nos diferentes estádios de desenvolvimento do arroz pré-germinado.

\section{Material e Métodos}

O Município de Gaspar, situado no médio Vale do Itajaí, a 2655'53"S, e 4857'32"W, à altitude média de
$18 \mathrm{~m}$, possui uma área de $369 \mathrm{~km}^{2}$. O clima classificase como mesotérmico úmido, com uma temperatura média anual de $20^{\circ} \mathrm{C}$. A produção de arroz na safra 2004/2005 foi de 29.440 t, em uma área plantada de 3.200 ha (Gaspar, 2005).

Para a realização do presente trabalho, foram escolhidas diferentes áreas de cultivo, denominadas de áreas de amostragem, que apresentaram características semelhantes em relação ao manejo da cultura de arroz pré-germinado. Nessas áreas, não ocorreram aportes de esgotos domésticos ou de resíduos provenientes de outras atividades agrícolas ou industriais.

A primeira área de amostragem (A1) tinha uma superfície aproximada de $7.666 \mathrm{~m}^{2}$. Sua localização é definida pelas coordenadas 0698986 UTM e 7016211 UTM, à altitude de 15 m. A água utilizada para a irrigação foi desviada do Ribeirão Gaspar Grande, e, posteriormente, foi devolvida, por um canal aberto, ao mesmo ribeirão. À montante do ponto de captação da água ocorre pouca ocupação urbana.

A segunda área de amostragem (A2), com uma área 67 ha, situa-se nas coordenadas 0700038 UTM e 7018509 UTM, à altitude de 11 m. Essa área é representada por dois grandes quarteirões, e pertence a uma associação de produtores de arroz, que desviam a água do Ribeirão Gaspar Grande para uma vala comunitária. Após o uso, a água é devolvida ao ribeirão, por meio de uma única saída. Esse ponto encontra-se à jusante da A1. A área apresenta-se bastante impactada, porque as lavouras se situam próximas ao Ribeirão.

A terceira área de amostragem (A3) tem aproximadamente de 35 ha, coordenadas 0703320 UTM e 7022943 UTM, e altitude de 14 m. A água usada é proveniente de uma nascente. À montante da captação existe uma área destinada à criação de gado de corte. A tomada da água é realizada por gravidade e, posteriormente, é devolvida ao mesmo corpo hídrico.

Realizou-se a determinação de parâmetros físicoquímicos da qualidade da água, na entrada e na saída das áreas, tais como: turbidez, $\mathrm{pH}$, condutividade, oxigênio dissolvido, demanda química de oxigênio (DQO), demanda bioquímica de oxigênio (DBO), fosfatos e nitrogênio total. O monitoramento foi realizado na safra 2004/2005. As amostras de água foram coletadas no momento em que os produtores colocaram ou retiraram a água. Foram realizadas duas coletas por mês, uma da água de irrigação e outra da água de drenagem, em datas e períodos diferentes em cada ponto de coleta, dependendo dos procedimentos de manejo adotados em cada área. 
Os procedimentos de coleta, conservação, transporte e análise foram feitos de acordo com Standard Methods APHA (Standard, 1998). As análises foram realizadas pelo Instituto de Pesquisas Tecnológicas de Blumenau, da Universidade Regional de Blumenau. Para a DBO, o método utilizado foi o HACH no 10.099. Para a DQO, utilizou-se o método HACH no 8.000. A turbidez e o OD foram determinados pelo Standard Methods APHA (Standard, 1998), e o fosfato foi determinado pelo método HACH no 8.180. Para o nitrogênio, utilizou-se o método Kjeldahl NBR 13796-Abril/97. A determinação da condutividade foi realizada com um condutivímetro e a do $\mathrm{pH}$ com um peagômetro digital.

Calculou-se o índice de qualidade de águas de Bascarán (IQAb), que proporciona o valor global de qualidade da água, ao incorporar valores individuais de uma série de parâmetros (Rizzi, 2001). Ele é expresso por:

$\mathrm{IQAb}=\mathrm{k} \sum_{\mathrm{i}=1}^{\mathrm{n}} \mathrm{C}_{\mathrm{i}} \mathrm{P}_{\mathrm{i}} / \sum_{\mathrm{i}=1}^{\mathrm{n}} \mathrm{P}_{\mathrm{i}}$

em que: $C_{i}$ é o valor porcentual correspondente ao parâmetro i; $\mathrm{P}_{\mathrm{i}}$ é o peso correspondente a cada parâmetro; e k é uma constante de ajuste, em função do aspecto visual da água, à qual se atribuiu: 1 para água clara, sem contaminação aparente; 0,75 para água com cor indefinida, espuma, pouca turbidez aparente ou natural; 0,50 para água com aparência de contaminação e forte odor; 0,25 para água negra, com fermentação e odor. $\mathrm{O}$ valor de $\mathrm{k}$ utilizado para a referida pesquisa foi de 0,75 para todas as áreas. Os valores de Ci e Pi são apresentados por Rizzi (2001).

O valor do IQAb varia de 0 a 100 e corresponde a uma escala qualitativa de caracterização, que vai do aspecto péssimo à excelente. O estabelecimento de tabelas similares, de acordo com o uso e avaliação específica, é recomendado (Rizzi, 2001).

\section{Resultados e Discussão}

O índice de qualidade de águas de Bascarán obtido para a água de irrigação e de drenagem, nas três áreas, englobando desde o preparo do solo até a soca, demonstrou que, tanto a água dos ribeirões quanto a da nascente entram nos quarteirões de arroz com qualidade imprópria (IQAb de 40 a 50). Esse fato pode estar associado ao uso e ocupação do solo, nas áreas situadas à montante do cultivo de arroz. A A3, que utiliza água de uma nascente, apresentou o IQAb, para a água de irrigação, com valores próximos à qualidade normal $(49,71)$.

A água de drenagem, nas três áreas, apresentou qualidade desagradável (IQAb de 30 a 40). Observou-se que a qualidade de água de drenagem ficou muito similar em todos os pontos de coleta. De acordo com análises físico-químicas, realizadas na safra 2004/2005, alguns parâmetros apresentaram valores elevados, para a água de irrigação e de drenagem (Tabela 1). A turbidez apresentou, em geral, valores elevados, durante o preparo do solo, tendo ficado acima do valor permitido pela Resolução 357/2005 do Conama (Brasil, 2005), para a água de classe 3 , destinada ao cultivo de cereais, que é de 100 UNT (unidade nefelométrica de turbidez). Observou-se que à medida que ocorre o desenvolvimento da planta, os valores de turbidez da água de drenagem tendem a diminuir.

Os resultados de turbidez corroboram os de Deschamps et al. (2003), em que as águas de drenagem sempre apresentaram valores superiores ao padrão

Tabela 1. Valores médios dos parâmetros físico-químicos das águas de irrigação e drenagem, em diferentes estádios de desenvolvimento do arroz irrigado, no Município de Gaspar, SC.

\begin{tabular}{|c|c|c|c|c|c|c|c|c|c|c|}
\hline \multirow[t]{2}{*}{ Parâmetros } & \multicolumn{2}{|c|}{ Preparo do solo } & \multicolumn{2}{|c|}{ Estádio vegetativo } & \multicolumn{2}{|c|}{ Estádio reprodutivo } & \multicolumn{2}{|c|}{ Estádio de maturação } & \multicolumn{2}{|c|}{ Soca } \\
\hline & Irrigação & Drenagem & Irrigação & Drenagem & Irrigação & Drenagem & Irrigação & Drenagem & Irrigação & Drenagem \\
\hline Turbidez (UNT) & 9,5 & $118,06^{(1)}$ & 8,24 & 30,43 & 9,05 & 28,53 & 6,70 & 16,00 & 7,6 & 15,83 \\
\hline $\mathrm{pH}$ & 7,93 & 7,75 & 7,72 & 7,80 & 7,38 & 7,77 & 7,99 & 7,65 & 6,95 & 7,53 \\
\hline $\begin{array}{l}\text { Condutividade } \\
\left(\mu \mathrm{Sm}^{-1}\right)\end{array}$ & 38,9 & 43,71 & 50,8 & 51,52 & 33,32 & 35,16 & 39,83 & 36,24 & 43,68 & 55,19 \\
\hline Fostato $\left(\mathrm{mg} \mathrm{L}^{-1}\right)$ & 0,06 & $0,16^{(1)}$ & $0,46^{(1)}$ & $0,5^{(1)}$ & 0,06 & $0,36^{(1)}$ & 0,06 & $0,16^{(1)}$ & $0,26^{(1)}$ & $0,17^{(1)}$ \\
\hline $\begin{array}{l}\mathrm{N} \text { amoniacal } \\
\text { total }\left(\mathrm{mg} \mathrm{L}^{-1}\right)\end{array}$ & 0,41 & 0,91 & - & 0,65 & 0,52 & 0,14 & 0,82 & 0,35 & 0,44 & 1,01 \\
\hline $\mathrm{OD}\left(\mathrm{mg} \mathrm{L}^{-1}\right)$ & 8,97 & 10,2 & 9,6 & 9,41 & 8,37 & 7,86 & 8,33 & 7,54 & 7,31 & 5,40 \\
\hline $\mathrm{DBO}\left(\mathrm{mg} \mathrm{L}^{-1}\right)$ & 16,2 & 19,07 & 28,18 & 62,3 & 7,46 & 15,03 & 19,56 & 32,46 & 31,81 & 12,03 \\
\hline $\mathrm{DQO}\left(\mathrm{mg} \mathrm{L}^{-1}\right)$ & 53,3 & 91 & 78 & 156,6 & 12 & 112,3 & 35,97 & 298,66 & 99,00 & 28,66 \\
\hline
\end{tabular}

(1) Valores superiores aos permitidos pela Resolução no 357/2005 do Conama para a água de classe 3. 
estabelecido pela Resolução do Conama. Valores altos de turbidez na água de drenagem são esperados, em razão das técnicas envolvidas no preparo do solo, para o plantio das sementes pré-germinadas (De Datta, 1981).

Em relação ao oxigênio dissolvido (OD), no período de soca, as concentrações na água de drenagem (5,4 $\left.\mathrm{mg} \mathrm{L}^{-1}\right)$ foram menores do que na água de irrigação. Isto pode ter ocorrido em função do elevado consumo de OD pelos microrganismos, no processo de decomposição da vegetação que ficou no solo em conseqüência do primeiro corte. No estádio vegetativo, a A3 apresentou OD, da água de irrigação, de 9,3 mg L-1, enquanto na água de drenagem foi de $12,6 \mathrm{mg} \mathrm{L}^{-1}$. Nessa área de amostragem, existe uma intensa assembléia de macrófitas aquáticas, da espécie Egeria densa (Hydrocharitaceae). Esta espécie caracteriza-se por ser excelente oxigenadora, pois possui intensa atividade fotossintética (Pelicice et al., 2005), o que pode explicar o aumento no OD. Observa-se também, que o OD sofre um decréscimo entre o preparo do solo a colheita.

O fosfato apresentou, em geral, para as águas de drenagem, diferenças significativas em determinados períodos, tendo seu maior valor no estádio vegetativo, período em que adubos químicos são aplicados. A DQO teve maior valor na fase de maturação e também teve valores maiores nas águas de drenagem do que nas águas de irrigação. Somente na durante a soca é que a água de irrigação apresentou maior DQO do que a água de drenagem. Os valores de nitrogênio amoniacal total foram muito abaixo do estabelecido pela Resolução 357/2005 para as águas de classe 3 , na quais o valor permitido é de 5,6 $\mathrm{mg} \mathrm{L}^{-1}$, para pH entre 7,5 e 8.

O índice de qualidade da água, nos diferentes estádios de desenvolvimento da planta, indicaram que, em relação ao preparo do solo, a qualidade da água de irrigação apresentou-se com qualidade normal nas áreas A2 e A3 (IQAb de 50 a 60) e com qualidade imprópria na A1 (IQAb de 40 a 50) (Tabela 2). Em relação à água de drenagem, na etapa de preparo do solo, a água apresentou-se desagradável nas áreas A1 e A3 (IQAb de 30 a 40), e imprópria na A2 (IQAb de 40 a 50). O decréscimo do IQAb, na água de drenagem, pode estar associado às técnicas de preparo do solo revolvimento, formação da lama e nivelamento -, que acarretam aumento na carga de sólidos em suspensão (Belder et al., 2004).

Durante o estádio vegetativo, as águas de irrigação e drenagem apresentaram qualidade desagradável (IQAb de 30 a 40). Somente na área A3, a água de irrigação apresentou-se imprópria (IQAb de 40 a 50). Ressaltase, no entanto, que os valores do IQAb, das áreas A1 e A2, estão muito próximos do valor considerado de qualidade imprópria.

No estádio vegetativo, os valores de turbidez da água não foram diferentes entre as águas de irrigação e de drenagem. O OD sempre teve valores elevados $\left(9,1,9,3,10,1 \mathrm{mg} \mathrm{L}^{-1}\right)$, talvez por ter sido influenciado pela formação da lâmina de água e altas intensidades luminosas, o que auxilia os processos fotossintéticos (Stone et al., 1990).

Alguns parâmetros, como os fosfatos, apresentaram valores elevados na água de drenagem $\left(0,5 \mathrm{mg} \mathrm{L}^{-1}\right.$ na A1, 0,7 mg L $\mathrm{m}^{-1}$ na $\mathrm{A} 2$ e $0,6 \mathrm{mg} \mathrm{L}^{-1}$ na A3), superiores aos valores da água de irrigação. Estes se encontram acima dos valores permitidos pela resolução do Conama no 357/2005, pela qual os valores permitidos são de $0,15 \mathrm{mg} \mathrm{L}^{-1}$ para as águas destinadas à irrigação de cereais (classe 3). Isto indica que a atividade orizícola está contribuindo para o aporte de nutrientes para as águas superficiais, o que também foi verificado por Belder et al. (2004).

Trabalhos realizados por Santos (1998) demonstraram que as perdas por fósforo são maiores que a média estabelecida pela resolução no 357/2005 do Conama, para as águas de classe 1 , nas quais as concentrações de fósforo total não devem ser superiores a $0,025 \mathrm{mg} \mathrm{L}^{-1}$. Outro parâmetro que apresenta diferenças significativas no estádio vegetativo, entre as águas de irrigação e de

Tabela 2. Qualidade de água, segundo o índice de qualidade de água de Bascarán (IQAb), nas diferentes etapas da cultura do arroz pré-germinado, na safra 2004/2005, no Município de Gaspar, SC.

\begin{tabular}{|c|c|c|c|c|c|c|}
\hline \multirow{2}{*}{$\begin{array}{l}\text { Etapas da } \\
\text { cultura do arroz }\end{array}$} & \multicolumn{2}{|c|}{ Área A1 } & \multicolumn{2}{|c|}{ Área A2 } & \multicolumn{2}{|c|}{ Área A3 } \\
\hline & Irrigação & Drenagem & Irrigação & Drenagem & Irrigação & Drenagem \\
\hline Preparo do solo & 41,77 & 33,26 & 42,64 & 40,20 & 52,90 & 34,66 \\
\hline Estádio vegetativo & 39,70 & 32,49 & 39,26 & 35,90 & 40,48 & 34,07 \\
\hline Estádio reprodutivo & 47,01 & 38,12 & 45,70 & 38,75 & 34,97 & 34,62 \\
\hline Estádio de maturação & 39,67 & 38,12 & 43,23 & 41,42 & 41,73 & 33,49 \\
\hline Soca & 40,12 & 36,76 & 35,45 & 35,38 & 78,46 & 57,85 \\
\hline
\end{tabular}


drenagem, é a DQO, cujos valores nas águas de irrigação foram: $170 \mathrm{mg} \mathrm{L}^{-1}$ na A1, $19 \mathrm{mg} \mathrm{L}^{-1}$ na A2 e $45 \mathrm{mg} \mathrm{L}^{-1}$ na A3. Na água de drenagem das áreas $\mathrm{A} 2$ e A3, as concentrações de DQO foram superiores. Na área A1, a DQO sofreu redução, enquanto a DBO manteve concentrações baixas. No período vegetativo, é feita a aplicação de herbicidas, adubação NPK e aplicação de uréia, o que pode explicar as elevações na DQO.

No estádio reprodutivo, a qualidade da água de irrigação nas áreas A1 e A2 foi caracterizada como imprópria (IQAb de 40 a 50), e na área A3, como desagradável. A água de drenagem, em todas as áreas, apresentou qualidade desagradável (IQAb de 30 a 40). Na área A3, um dos parâmetros que sofreu alteração entre as águas de irrigação e drenagem foi a turbidez (9,14 UTN e 57,6 UTN). A água da área A2 apresentou valores superiores de DQO na drenagem $\left(13 \mathrm{mg} \mathrm{L}^{-1}\right.$ na água de irrigação e $266 \mathrm{mg} \mathrm{L}^{-1}$ na água de drenagem). Neste período, a água de drenagem da área A1 apresentou diminuição da concentração de OD (8,78 $\mathrm{mg} \mathrm{L}^{-1}$ na água de irrigação e 7,87 $\mathrm{mg} \mathrm{L}^{-1}$ na água de drenagem).

No estádio de maturação, os resultados para as áreas A2 (irrigação e drenagem) e A3 (irrigação) revelaram qualidade de água classificada como imprópria. Na área A1 a água de irrigação apresentou qualidade normal, mas a água de drenagem, tanto da área A1 como da A3, apresentou qualidade desagradável. Em geral, as concentrações de OD diminuíram. A DQO, nas três áreas amostradas, apresentou valores maiores na água de drenagem do que na de irrigação. Tanto a diminuição do OD como o aumento da DQO podem ter ocorrido como conseqüência dos processos de decomposição das estruturas foliares da planta do arroz próximo à lâmina d’água (Santos et al., 2002).

Na soca, a água de irrigação apresentou, em média, qualidade normal (IAQb de 51,34). A água da área A3 apresentou o maior valor do IQAb $(78,46)$, que classifica a água como agradável, o que deveria ter ocorrido em toda a água de irrigação desta área, visto que é oriunda de uma nascente. A água de drenagem apresentou, em geral, qualidade imprópria (IQAb médio de 43,33).

Observa-se que, de modo geral, a qualidade da água de irrigação variou de desagradável à imprópria. Somente na fase que antecedeu o preparo do solo, a qualidade da água apresentou-se como normal nas áreas A2 e A3 e, na soca, como agradável na A3.

Deschamps et al. (2003) demonstraram que a qualidade da água de drenagem, determinada pelo IQA, foi classificada como ruim e péssima em $83,2 \%$ das amostras analisadas e boa a excelente em $16,8 \%$ das amostras. O que não ocorreu neste trabalho, pois, na maioria das análises realizadas, a qualidade da água ficou classificada como desagradável à imprópria, segundo o IQAb. Toledo et al. (2002) também demonstraram que ocorre um gradiente de degradação da qualidade da água no sentido de fluxo de irrigação para drenagem.

O índice de qualidade de água de Bascarán, determinado em cada período de desenvolvimento da rizicultura, revelou as maior variação na qualidade da água na fase de preparo do solo, em que os valores foram maiores na água de irrigação do que de drenagem. No preparo do solo, a variação média ficou em torno de 9,7; no estádio vegetativo foi 5,6; no estádio reprodutivo, 6,4; no estádio de maturação, 3,9; e na soca, 8. Constatou-se que as maiores diferenças na qualidade da água de irrigação e drenagem ocorrem no período de preparo do solo e na soca. Assim, pode-se dizer que a cultura orizícola não acarreta grandes alterações na qualidade da água de drenagem, quando comparada à qualidade da água usada para irrigação.

\section{Conclusões}

1. O sistema de plantio de arroz pré-germinado não acarreta grande alteração na qualidade da água, quando comparada à qualidade das águas de irrigação e de drenagem.

2. A demanda química por oxigênio, a turbidez e os fosfatos são elevados na água de drenagem.

3. A maior degradação da qualidade da água é observada na fase de preparo do solo e na soca.

\section{Agradecimentos}

Ao CNPq, pela bolsa concedida a Joseline Molozzi; ao CT-Hidro, pelo financiamento deste trabalho.

\section{Referências}

AZAMBUJA, I.H.V.; VERNETTI JUNIOR, R.F.J.; MAGALHÃES JUNIOR, A.M. de. Aspectos socioeconômicos da produção do arroz. In: GOMES, A. da S.; MAGALHÃES JÚNIOR, A.M. de (Ed.). Arroz irrigado no Sul do Brasil. Brasília: Embrapa Informação Tecnológica, 2004. p.75-96.

BELDER, P.; BOUMAN, B.A.M.; CABANGON, R.; GUOAN, L.; QUILANG, E.J.P.; YUANHUA, L.; SPIERTZ, J.H.J.; TUONG, T.P. Effect of water-saving irrigation on rice yield and water use in typical lowland conditions in Asia. Agricultural Water Management, v.65, p.193-210, 2004. 
BETHUNE, M.; AUSTIN, N.; MAHER, S. Quantifying the water budget of irrigated rice in the Shepparton Irrigation Region, Australia. Irrigation Science, v.20, p.99-105, 2001.

BRASIL. Ministério do Meio Ambiente. Conselho Nacional do Meio Ambiente. Resolução no 357 de 17 de março de 2005. Diário Oficial da União, 18 mar. 2005. Disponível em <http://www.mma.gov.br/port/conama/res/res05/res35705.pdf>. Acesso em: 20 set. 2006.

COSTA, E.G. de C.; SANTOS, A.B. dos; ZIMMERMANN, F.J.P. Características agronômicas da cultura principal e da soca de arroz irrigado. Ciência e Agrotecnologia, v.24, p.15-24, 2000.

DE DATTA, S.K. Principles and practices of rice production. New York: J. Wiley, 1981. 618p.

DESCHAMPS, F.C.; TOLEDO, L.G.; NOLDIN, J.A. Índice de qualidade de águas (IQA) na avaliação do impacto da cultura do arroz irrigado sobre a qualidade das águas superficiais. In: CONGRESSO BRASILEIRO DE ARROZ IRRIGADO, 3., 2003; REUNIÃO DA CULTURA DO ARROZ IRRIGADO, 25., 2003. Anais. Porto Alegre: Instituto Rio Grandense do Arroz, 2003. p.700-702.

GASPAR (Santa Catarina). Conheça Gaspar: coordenadas geográficas. Disponível em: <http://www.cidadedegaspar.com.br>. Acesso em: maio 2005.

MOLOZZI, J.; SILVA, A.; PINHEIRO, A.; HEPP, L.U. A cultura do arroz influenciando a distribuição de macrófitas aquáticas. Perspectiva, v.29, p.61-68, 2005.

PELICICE, F.M.; AGOSTINHO, A.A.; THOMAZ, S.M. Fish assemblages associated with Egeria in a tropical reservoir: investigating the effects of plant biomass and diel period. Acta Oecologica, v.27, p.9-16, 2005.

PETRINI, J.A.; FRANCO, D.F.; SOUZA, P.R. de; BACHA, R.E.; TRONCHONI, J.G. Sistema de cultivo de arroz pré-germinado e transplante de mudas. In: GOMES, A. da S.; MAGALHÃES JÚNIOR, A.M. de (Ed.). Arroz irrigado no Sul do Brasil. Brasília: Embrapa Informação Tecnológica, 2004. p.387-416.

RIZZI, N. Índices de qualidade de água. Sanare, v.15, p.13-25, 2001.

SANTOS, A.B. dos. Aproveitamento da soca. In: VIEIRA, N.R. de A.; SANTOS, A.B. dos; SANT'ANA, E.P. (Ed.). A cultura do arroz no Brasil. Santo Antônio de Goiás: Embrapa-CNPAF, 1998. p.147-149.

SANTOS, A.B.; FERREIRA, E.; STONE, L.F.; SILVA, S.C.; RAMOS, C.G. Manejo de água no comportamento da cultura principal e da soca de arroz irrigado. Pesquisa Agropecuária Brasileira, v.37, p.1413-1420, 2002.

STANDARD methods for the examination of water and wastewater. $19^{\text {th }}$ ed. Washington: APHA: AWWA: WEF, 1998. 1v.

STONE, L.G.; MOREIRA, J.A.A.; SILVEIRA FILHO, A. Manejo de água na cultura do arroz: consumo, ocorrência de plantas daninhas, absorção de nutrientes e características produtivas. Pesquisa Agropecuária Brasileira, v.25, p.323-337, 1990.

TOLEDO, L.G.; DESCHAMPS, F.C.; NICOLELLA, G.; NOLDIN, J.A.; EBERHARDT, D.S. Impacto ambiental da cultura do arroz irrigado com o uso de índice de qualidade de água (IQA). Jaguariúna: Embrapa Meio Ambiente, 2002. 3p. (Embrapa Meio Ambiente. Comunicado técnico, 8).

Recebido em 3 de agosto de 2005 e aprovado em 26 de julho de 2006 